\title{
A Review: Cyanthillium cinereum (L) H. Rob.
}

\author{
Ramya C. ${ }^{1}$, Vishnu $\mathrm{AS}^{2}$, Nasila $\mathrm{K}^{3}$ \\ ${ }^{1,3}$ Final Semester, M. Pharm Student, ${ }^{2}$ Lecturer, \\ College of Pharmaceutical Sciences, Govt. Medical College, Kannur, Kerala.
}

Corresponding Author: Ramya C.

\begin{abstract}
Cyanthillium cinereum (L) H. Rob (family Asteraceae) is also known as Poovamkurunnila in Malayalam. It is commonly found as a weed throughout in India. Cyanthillium cinereum is an annual herb with hairy stem, up to $12-75 \mathrm{~cm}$ height. The leaves are simple, alternate, ovateelliptic or acute, irregularly dentate or crenateserrate and hairy.

Cyanthillium cinereum is an annual herb, contains various phytochemicals like cardiac glycosides, phenols, flavonoids, steroids, tannins, saponins and phlobatannins etc. Due to the presence of these phytochemicals Cyanthillium cinereum exhibits various activities like analgesic, antibacterial, antioxidant, anticancer, antispasmodic, antimalarial and antifungal etc.
\end{abstract}

Keywords - Cyanthillium cinereum (L) H. Rob, Pharmacological activities, Therapeutic use.

\subsection{INTRODUCTION}

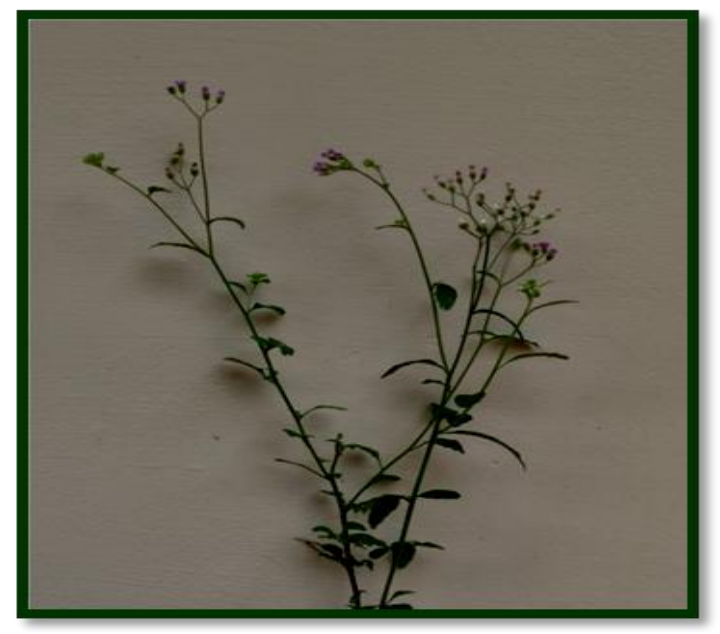

Fig 1: Cyanthillium cinereum whole plant

Cyanthillium cinereum (L) H. Rob. [1] (family Asteraceae) is also known as
Poovamkurunnila in Malayalam. It is commonly found as a weed throughout in India. Cyanthillium cinereum is an annual herb with hairy stem, up to $12-75 \mathrm{~cm}$ height. ${ }^{[2]}$ The leaves are simple, alternate, ovateelliptic or acute, irregularly dentate or crenate-serrate and hairy. The whole plant of Cyanthillium cinereum is shown in Fig 1.

Phytochemical screening of Cyanthillium cinereum revealed the presence of cardiac glycosides, phenols, flavonoids, steroids, tannins, saponins and phlobatannins ${ }^{[2]}$.

Leaves of Cyanthillium cinereum (L) H. Rob have various medicinal properties such as analgesic [3], antipyretic [4], anti bacterial ${ }^{[5]}$ and antifungal effect ${ }^{[6]}$. Fresh leaves of Cyanthillium cinereum were extracted with various solvents like petroleum ether, ethanol and distilled water for analyzing the phytoconstituents. Phytochemical screening revealed that more active principles like phenol, tannins, saponins, alkaloids, terpenoids etc. were found in ethanolic extract of Cyanthillium cinereum. ${ }^{[7]}$.

\subsection{Pharmacological Activities of Cyanthillium cinereum (L) H. Rob.}

Cyanthillium cinereum have antibacterial, antioxidant, anticancer, antispasmodic and antimalarial activities.

\subsection{Antibacterial activity ${ }^{[8,9]}$}

Crude methanolic extract of Cyanthillium cinereum exhibits antibacterial activities against Staphylococcus aureus, Escherichia coli, Pseudomonas aeruginosa and bacillus subtilis. 
The Cyanthillium cinereum plant extract showed significant antibacterial activity. The strong anti bacterial activity of Cyanthillium cinereum plant extract is due to the presence of phytochemical compounds such as flavonoids, phenols, tannins and saponins.

\subsection{Antioxidant activity ${ }^{[10,11]}$}

Hexane, chloroform, methanolic and aqueous crude extracts of Cyanthillium cinereum exhibited potent antioxidant property. Phytochemical constituents scavenge different free radicals and provide a protective action against oxidative damage to biological macromolecules. The antioxidant activity exhibited by Cyanthillium cinereum could be due to presence of flavonoids, polyphenolic compounds and tannins.

\subsection{Anticancer activity ${ }^{[8]}$}

Crude ethanolic extract of Cyanthillium cinereum were tested for anticancer activity in MCF-7 breast cancer cell lines. The leaf extract of Cyanthillium cinereum exhibited high anticancer activity.

\section{Cell Apoptosis Assay}

Cyanthillium cinereum plant extract induced cell death by apoptosis in MCF-7 breast cancer cells.

MTT (3-(4, 5-dimethylthiazolyl-2) 2, 5diphenyltetrazolium bromide) Assay

Cyanthillium cinereum plant extract exhibited significant reduction in cell viability.

\subsection{Antispasmodic activity ${ }^{[12]}$}

Ethanolic extract of leaves of Cyanthillium cinereum possess high degree of antispasmodic activity by blocking cholinergic receptors. Cyanthillium cinereum exhibits comparable antispasmodic activity of standard antispasmodic agent (Atropine). Cyanthillium cinereum being a herbal origin drug with high degree of safety and efficacy could be used as a suitable alternative for existing drugs.

\subsection{Anti malarial activity ${ }^{[10]}$}

Due to the presence of Sesquiterpene lactones, Cyanthillium cinereum possess anti malarial activity.

\subsection{Therapeutic uses of Cyanthillium cinereum (L) H. Rob}

Cyanthillium cinereum has

therapeutic potentials against;

- Fever

- Malaria

- Asthma

- Cancer

- Cholera, colic pain, cough, diarrhea

- Leprosy and chronic skin diseases

- Conjunctivitis

- Arthritis

- Rheumatism

\subsection{CONCLUSION}

Cyanthillium cinereum is an annual herb, contains various phytochemicals like cardiac glycosides, phenols, flavonoids, steroids, tannins, saponins and phlobatannins etc. Due to the presence of these phytochemicals Cyanthillium cinereum exhibits various activities like analgesic, antipyretic, antibacterial, anti oxidant and antifungal effect.

Acknowledgement: None

\section{Conflict of Interest: None}

\section{Source of Funding: None}

\section{REFERENCES}

1. Botanical name. Available from: http://www.theplantlist.org/tpl1.1/record/qc c-149577.

2. Shruthi Roy, Madhu K P, Jyolsna G Krishna. Pharmacognostical and phytochemical evaluation of the drug sahadevi (Cyanthillium cinereum (L.) $\mathrm{H}$. Rob.). International Journal of Ayurveda and Pharma Research; 2019: 7 (9).

3. Thitiya Luetragoon, Rungnapa Pankla Sranujit , Chanai Noysang, Yordhathai Thongsri , Pachuen Potup , Jukarin 
Somboonjun et al., Evaluation of AntiInflammatory Effect of Moringa oleifera Lam. and Cyanthillium cinereum (Less) $\mathrm{H}$. Rob. Lozenges in Volunteer Smokers. Plants 2021, 10, 1336. https://doi.org/10.3390/plants10071336.

4. Iwalewa, E.O.; Iwalewa, O.J.; Adeboye, J.O. Analgesic, antipyretic, antiinflammatory effects of methanol, chloroform and ether extracts of Vernonia cinerea less leaf. J. Ethnopharmacol. 2003, 86, 229-234.

5. Joshi, T.; Pandey, S.C.; Maiti, P.; Tripathi, M.; Paliwal, A.; Nand, M.; Sharma, P.; Samant, M.; Pande, V.; Chandra, S. Antimicrobial activity of methanolic extracts of Vernonia cinerea against Xanthomonas oryzae and identification of their compounds using in silico techniques. PLoS ONE 2021, 16, e0252759.

6. Yusoff, S.F.; Haron, F.F.; Tengku Muda Mohamed, M.; Asib, N.; Sakimin, S.Z.; Abu Kassim, F.; Ismail, S.I. Antifungal Activity and Phytochemical Screening of Vernonia amygdalina Extract against Botrytis cinerea Causing Gray Mold Disease on Tomato Fruits. Biology 2020, 9, 286.

7. SureshS.N,Varsha.V,Prajeena.V.Phytochem ical screening of Cyanhilium cinereum leaf extract .International journal of medicine and pharmaceutical research. 2015, 3(61):1238-1241.

8. Suja.S, Iwin .C,Varkey.Medicinal and pharmacological values of Cyanthillium cinereum extract : investigate the antibacterial and anticancer activity in MCF-7 Breast cancer cell lines.International journal of research an analytical reviews .2012;6(1):2348-1269.

9. Ourlad A.G.Tantengco,Marlon Lian C.Condes, Hanna Hasmin T.Estadilla,Elena M.Ragragro.Antibacterial activity of vitex parviflora A.juss and Cyanthillium cinereum (L.)H.Rob. against human pathogens.Asian pacific journal of Tropical Diseases.2016; 6(12) :1004-1006.

10. Gunjan Guha, V.Rajkumar,and Lazar Mathew.Therapeutic potential of polar and nonpolar extracts of Cyanthillium cinereum In Vitro.Evidence based complementary and alternative medicine.;2011.doi:10.1093/ecam/nep155.

11. Nishadh,Selvi V,Mahalakshmi R.In vitro antioxidant and phytochemical screening of various extracts of vernonia cinerea leaves.Int J Drug Dev Res.2013;5(3):227230.

12. Swetha.B, Prathibha.B.Evaluation of antioxidant activity of ethanolic extract of leaves of Cyanthillium cinereum (L) H.Rob.by using isolated frog heart.IJPPR. 2018; 12(3).

How to cite this article: Ramya C., Vishnu AS, Nasila K.. A review: Cyanthillium cinereum (1) h. rob.. International Journal of Research and Review. 2021; 8(9): 99-101. DOI: https://doi. org/10.52403/ijrr.20210914 